\title{
Components of functional-structural tree models
}

\author{
Risto Sievänen ${ }^{\mathrm{a}, *}$, Eero Nikinmaa ${ }^{\mathrm{b}}$, Pekka Nygren ${ }^{\mathrm{b}}$, Harry Ozier-Lafontaine ${ }^{\mathrm{c}}$, \\ Jari Perttunen ${ }^{\mathrm{a}}$ and Harri Hakula ${ }^{\mathrm{d}}$ \\ a Vantaa Research Centre, Finnish Forest Research Institute, 01301 Vantaa, Finland \\ ${ }^{\mathrm{b}}$ Department of Forest Ecology, University of Helsinki, Finland \\ ${ }^{c}$ Unité Agropédoclimatique de la Zone Caraïbe, INRA Antilles-Guyane, France \\ ${ }^{\mathrm{d}}$ Department of Mathematics, Helsinki University of Technology, Finland
}

(Received 1 February 1999; accepted 28 October 1999)

\begin{abstract}
We analyze functional-structural tree models (FMSs) that are an outgrowth of developments in process-based models (PBMs) on the one hand, and morphological models on the other. Existing morphological and functional-structural models are briefly reviewed. We introduce the idealized elementary unit (IEU) that can be used as the basic component of a FSM, and pinpoint the processes that have to be accounted for. The distribution of metabolites and growth is identified as one of the main focal points to be investigated in conjunction with FSMs, and the different approaches that can be applied in constructing the model component for this process are presented. Finally, we analyze the computational requirements of FSMs, discuss the challenges they pose, and assess their applicability in a number of different tasks.
\end{abstract}

functional-structural model / process-based model / morphological model / tree structure / L-system

Résumé - Les composants des modèles fonctionnels et structuraux des arbres. Cet article a pour objet de faire une synthèse des approches réalisées dans le cadre de la modélisation fonctionnelle et structurale des arbres (FSM). Ces modèles résultent du couplage entre la modélisation du fonctionnement écophysiologique d'arbres, d'une part, et la modélisation des processus morphologiques, d'autre part. Après une brève présentation des approches existantes, nous introduisons la notion «d'unité élémentaire idéale» (IEU) qui peut être considérée comme la composante fondamentale des FSM au regard de la souplesse qu'elle confère dans l'articulation des processus. La distribution des métabolites et la croissance sont ensuite abordées comme étant les processus à résoudre de façon prioritaire dans le développement des FSM, et les différentes approches pouvant être mises à contribution dans la construction de ces modèles sont discutées. Enfin nous analysons les besoins en programmation des FSM, discutons des avancées nécessaires et évaluons leur adéquation à la résolution d'objectifs divers.

modèle fonctionnel-structural / modèle de fonctionnement / modèle morphologique / structure des arbres / L-system

\section{INTRODUCTION}

Process-based models (PBMs) are tools for analyzing tree and forest stand performance and growth [50,51]. They emulate physiological processes and give a detailed account of metabolism and plant growth in terms of mass variables. Growth is normally derived from the carbon balance (based on photosynthesis, respiration and resource allocation) and the factors and processes which affect it (nutrient cycling, seasonality, possibly

* Correspondence and reprints

Tel. +358-9-85705373; Fax.+358-9-85705361; e-mail: risto.sievanen@metla.fi 
transpiration and water relations). A typical application of a PBM might be the prediction of the possible effects of climate changes, and change in the chemical composition of the atmosphere, on future forest growth [e.g. 27, 65]. These models are suitable for this purpose because growth in the models is the result of processes that are likely to be affected by such factors.

The architectural structure of trees has usually been described in the PBMs in a less detailed manner. A typical case might be one in which the dimensions of the trunk and branches are presented using a limited number of variables and foliage is taken into account by the biomass. However, it has become evident that the 3D structure of the tree strongly affects the processes included in the PBMs. The 3D-crown structure affects the distribution of carbohydrates between productive and non-productive tissues [30,69], the light interception properties of trees, and the gas-exchange properties of the foliage [51]. Furthermore, these processes provide the feedback that influences the growth of individual shoots.

In the geometric models of the structural dynamics of plants, "the spatial position and orientation of each structural component is tracked. This allows the simulation of position-specific interactions such as collisions between branches, interception of light by leaves and bending of branches due to gravity. Geometric models also provide the information necessary for realistic images of virtual plants to be produced..." as stated by Room et al. [87]. The geometric - also called morphological - models have utilized L-systems [80] or other mathematical means (e.g. [41]) to present a tree as a collection of modules, which is evolved by the application of basic morphological rules. Many studies on tree structure have emphasized the modularity of trees, i.e. how the trees - and other vascular plants - are composed of a number of repetitive units or modules [reviewed in 16 and 87]. As such, the morphological models have been constructed directly on the basis of research carried out on the regularities and structural units of plant architecture [41].

The combination of PBMs and morphological models (as suggested by Kurth [48]) can be seen as a new development. Models which have features characteristic of PBMs and morphological models, that treat plants as assemblage of elementary units or modules, have emerged. This kind of model can be called functionalstructural model ${ }^{1}$ (FSM). They bridge the gap between PBMs and tree architecture models by depicting the true 3D presentation of plants for use in analyzing plant behavior. The FSMs open up new possibilities to investi-

${ }^{1}$ They have also been called virtual plants [35]. gate phenomena that could not be studied with previous generations of plant models. Since the FSMs contain an explicit description of the plants, they are especially well suited for studying questions related to the structural dynamics of plants and plant-environment interactions in heterogeneous environments. Detailed description of the plant architecture facilitates accurate estimation of actual resource uptake and, most of all, it facilitates the estimation of the limits on organ growth set by resource uptake and tree-like growth habit. However, due to the detailed description of the plant structure and, consequently, of the local environment of each organ, the model is computationally heavy.

In this paper we analyze the FSMs and their components but do not attempt to review each facet of these models. Instead we discuss some topics associated with the construction of FSMs, primarily modeling the distribution of growth. Finally we discuss computational aspects and the challenges posed for FSMs. Owing to our background in tree research, we mainly focus on tree models. We are aware that the majority of the points we made about tree models could also be made about plant models in general.

\section{FUNCTIONAL-STRUCTURAL MODELS (FSMS)}

\subsection{Two approaches to a FSM}

The FSMs contain descriptions of metabolic (physiological) processes that are combined in the presentation of the 3D structure of the tree. The architectural structure of the model tree is presented on the basis of a small number of elementary units. We use the notion of elementary unit, but the names basic unit, module, basic element, or structural unit have also been used. The structural dynamics of the tree are based on the proliferation and growth of the elementary units, and is affected by the metabolic processes (figure 1).

The construction of the FSMs varies from case to case, but it would appear that there are roughly two ways of ending up with a FSM: to start from a geometric model of structural dynamics and add the physiological details to it, or to start from a PBM and increase the structural detail. Both groups of models are shortly reviewed in the following sections. The root models are reviewed separately. More comprehensive accounts of existing models can be found elsewhere [e.g. 25 and 87]. 


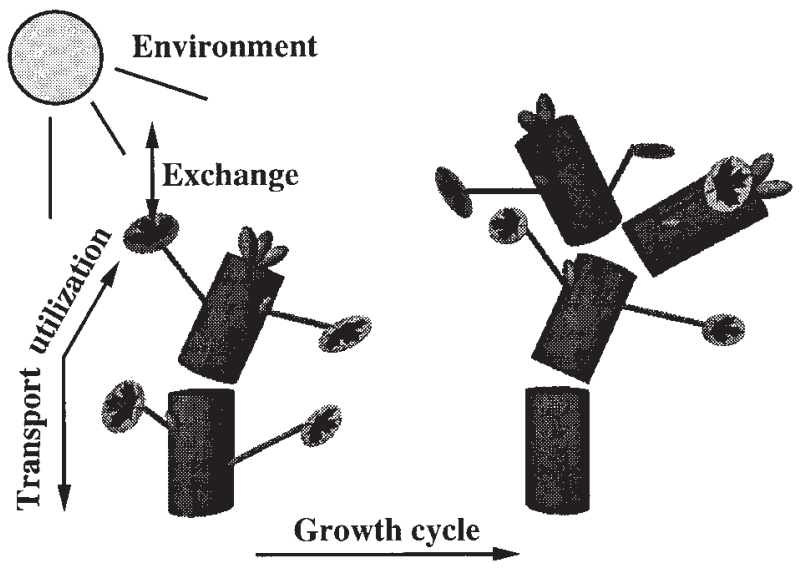

Figure 1. Schematic presentation of the structure of a FSM. The plant (only above-ground parts) consists of the elementary units segment, leaf and bud. The processes (effect of environmental factors, exchange of matter with the environment, and transport and conversion activities) that determine the growth rate of dryweight are indicated on the left. In one growth cycle new units are added (the buds flush), the number and size being determined on the basis of the outcome of growth processes, on the right. The growth of individual elements may be modeled as a continuous process (the size changes continuously) or as a discrete process in which the size of the units changes in accordance with the growth cycle.

\subsubsection{Morphological models}

There are a number of mathematical methods for describing structural dynamics in 3D space. The L-systems $[47,80]$ are obviously the most well known and widely used method. It is fairly straightforward to generate $3 \mathrm{D}$ plants using L-systems, and several examples of simulations and realistic visualization of plants exist [47, 80, 81]. However, the L-system formalism as originally introduced is not flexible enough to handle different tree architectures or the tree-environment interaction [47]. Consequently, extensions of L-system formalism have been introduced [49, 61, 80, 81], e.g. context sensitive Lsystems, parametric L-systems, or open L-systems. They permit the introduction of interactions between the elementary units and modeling interactions with the environment. In this way, the advanced L-systems make it possible to build FSMs. Plant modeling systems are available that are based on advanced versions of L-systems, e.g. GROGRA [47] and Vlab [62]. The Botanical Plant Modeling System [52] uses a parametric L-system framework for the modeling and measurement of plant structure.

The modeling group AMAP at CIRAD in France has created a plant modeling and visualization system that can produce very realistic plant images. The system uses a mathematical description of the development of plant morphology $[41,83]$. The growth rules are analyzed from measurements of plant structure. A plant modeling system AMAPmod [31] has been developed for this purpose, and it permits a wide range of analyses to be made on plant structure. The mathematical growth engine AMAPpara that incorporates physiological processes (photosynthesis, transpiration) and their effect on growth and its distribution has recently been developed $[84,85]$. It is flexible and realistically describes plant morphology and can be used to study e.g. the hydraulic resistance of the transport path, photosynthetic production and the carbon limitation of growth.

\subsubsection{Models utilizing process-based relationships}

The models utilizing process-based relationships define the PBMs for a detailed 3D structural resolution and thus apply the approach of figure 1 in a specific form. These models usually use ad hoc mathematical formalisms to present a 3D tree that consists of elementary units.

Kellomäki and Strandman [45] related shoot growth and the production of new shoots in Scots pine to the light climate of the parent shoot. The other parts of the tree (older shoots) increase their diameter in order to maintain biomechanical stability of the tree. This model thus allows investigations on e.g. the effects of radiation and branching habit on the growth dynamics of Scots pine crowns.

Takenaka [100] is also using the local light climate as the controlling factor of shoot (Takenaka's term: branch unit) production. Branching geometry is fixed. This model was not fixed to any specific tree species but it is generic. Takenaka studied the effect of different patterns of growth allocation between daughter shoots and the effect of the competition from neighboring trees on the structural dynamics of the tree crown.

The model LIGNUM $[78,79,96]$ combines a PBM with a detailed description of the tree crown. The photosynthetic production of tree parts depends on their local light climate. Respiration and consumption by roots is considered in the carbon economy. The carbon for growth is partitioned using the pipe model theory (cf. 3.2.9) and empirical relationships. Branching takes place on the basis of simple rules. The model has been applied to Scots pine and used to investigate the effect of different physiological traits and branching habits on tree growth.

The model MADEIRA [46] simulates the radiation absorption and carbon gain of a tree using a PBM approach. After subtracting maintenance requirements, the distribution of assimilates available for growth are 
divided between the parent and daughter branch units and other tree parts according to the measured relationships. The branching pattern is not fixed, but several tree species can be simulated by applying various plant growth forms.

The models ECOPHYS [82] and SIMWAL [21] incorporate a very detailed PBM into a 3D structural description. They simulate the structural dynamics of poplar and walnut trees, respectively, at a fine temporal resolution (time step is a fraction of day). They also apply a detailed submodel for the distribution of assimilates. These models are therefore able to simulate the effects of physiology on tree growth on a fine scale. So far, the computationally heavy ECOPHYS model has been applied to seedlings and saplings of Populus spp and SIMWAL to walnut trees.

Breckling [10] has developed an object oriented approach [cf. 88] to FSMs in a generic plant model. This model presents each plant organ with its own object (instance of a class), which then captures environmental resources, runs metabolic functions and exchanges substances with other objects. This approach is applied both above and below-ground. The environment of the model plant is realized using discretization of the $3 \mathrm{D}$ space (voxel space approach). So far, the model has been applied to seedlings [23] and root systems [63].

\subsubsection{Root models}

Since the pioneering work of Lungley [54], who developed a numerical 2D model to simulate the growth of a root system, the modeling of 3D-root architecture has been a subject of a particular attention during the last decade. Different types of model dedicated to a number of species have been developed using explicit approaches $[17,19,26,73$, and 75], or by utilizing the fractal properties of root systems [9, 67, 74, 92]. Recent research results allow us to consider the influence of a variety of environmental factors in the soil on root growth and development, e.g. soil moisture, temperature and aeration [42]. The model of Clausnitzer and Hopmans [17] was the first that allowed the simulation of $3 \mathrm{D}$ plant root activity as controlled by the physical conditions in the soil environment and water uptake. More recently, Měch and Prusinkiewicz [61] proposed a virtual model of root development by linking a simplified version of the previous approach in environment modeling with a root model built with open L-systems. The models of Nielsen et al. [68] (SimRoot) and Clausnitzer and Hopmans [17] are the only ones taking into account related root architecture and carbon allocation. In fact, SimRoot attempts to study the influence of the root architecture on the carbon investment, and not the influence of the carbon availability on root development.

\section{MODELING THE STRUCTURE AND FUNCTION IN FSMS}

In this chapter we examine how both functional and structural aspects of tree development can be modeled in terms of an elementary unit. The functional aspects of tree development are the capture of resources and the distribution of growth (in terms of mass). We analyze the distribution of growth in greater length. The reason for this is that there is a considerable amount of literature and models concerning resource capture $[20,50,51,105]$ and the structural development of trees (e.g. [32, 34, 47, and 80]). We feel, however, that the distribution of growth is a central - and maybe a less well studied - component of the FSMs.

\subsection{An elementary unit and its processes}

The description of the architectural structure in a FSM is, in principle, straightforward. The tree is simply a collection of elementary units. The way in which several elementary units form larger structures (branches etc.) has been treated from the theoretical point of view in a number of papers [31-33, 88, and 80]. An idealized elementary unit (IEU) that allows for the description of both the $3 \mathrm{D}$ structure and metabolic processes is the most useful one for a FSM. A successful IEU should permit simplification and aggregation of the real biological processes and tree structure for the purposes of modeling. It should thus make it possible to grasp the essential phenomena and to neglect the unimportant ones. The properties of an IEU that would be appropriate for a FSM are the following at least:

1. The IEU is morphologically repeated in a tree; in an ideal case only an above-ground and a below-ground IEU should be needed for describing the tree structure;

2. The functioning of an IEU depends on responses to the local environment and its neighboring IEUs; metabolic processes can be modeled as local assimilation and conversion processes, or as material exchange between the neighboring units or the unit and its local environment. The physiological aging of an elementary unit causes structural changes in it, which result in gradual changes in the whole tree structure;

3. Adjacent IEUs form a continuous transport medium for water and solutes in which the transport properties of each unit depend on their structure and physiological stage. The transport properties of the tree are an integral result of the properties of all IEUs;

4. The IEU should be small enough to allow its micro environment to be treated as spatially homogeneous, but it should be large enough to ensure that the number 
of units does not become prohibitively large when simulating big trees.

Analyses of plant architecture have suggested a number of possible elementary units, such as the metamer and growth unit $[16,87]$. A metamer is defined as an internode with axillary bud(s) and leaf (leaves) in its upper end, but without any shoots resulting from growth of the axillary buds [16]. A computational simplification of a metamer has been presented Rey et al. [86]. A growth unit, initially called a unit of extension by Hallé et al. [34], is the part of the shoot resulting from uninterrupted extension growth. Room et al. [87] describe it as "extension of the contents of a previously dormant apical bud followed by growth of neoformed leaves (if any) and formation of a new, dormant, apical bud". An axis, "a sequence of growth units in the same general direction from one (monopodial) or more (sympodial) meristems" [87], is another morphological unit of interest in tree modeling.

Our proposal for the above-ground IEU of broadleaved trees is morphologically a metamer as defined by Caraglio and Barthélémy [16] (figure 2). The internode is composed of bark, sapwood and heartwood. The structural changes of the internode from poorly differentiated young tissue to sapwood and heartwood should be taken into account when modeling the aging of the IEU. Further, we propose to use a growth unit rather than a metamer as the IEU for conifers, because of the small size and consequent high density of the needles (figure 2). Axillary buds are seldom formed with each needle, especially in Pinus spp. [16]. For example, in the LIGNUM model of Scots pine $[78,79]$, the construction that corre-

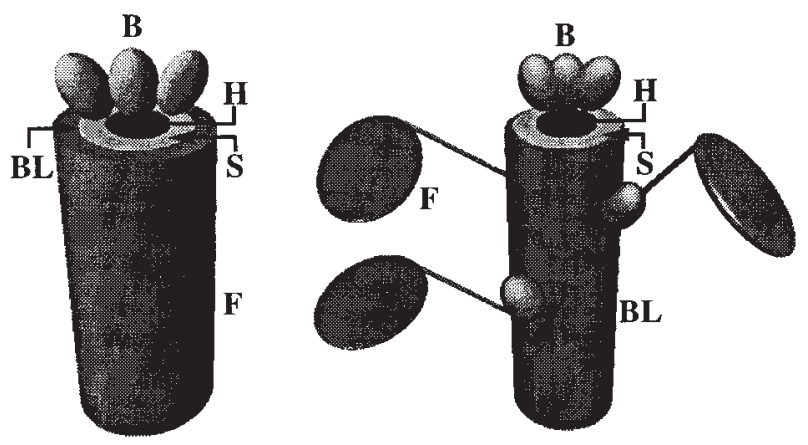

Figure 2. An idealized above-ground elementary unit (IEU) for a broad-leaved tree (on the right) and for a coniferous tree (on the left). The deciduous IEU contains a woody part with bark (BL), sapwood (S), and heartwood (H). It also has leaves (F), and buds (B). The coniferous IEU contains a woody part (with bark (BL), sapwood $(\mathrm{S})$ and heartwood $(\mathrm{H})$ ) that is surrounded by a cylinder of needles (F) and has buds (B) at the end. Dependeding on the age of the IEU the buds can be missing.

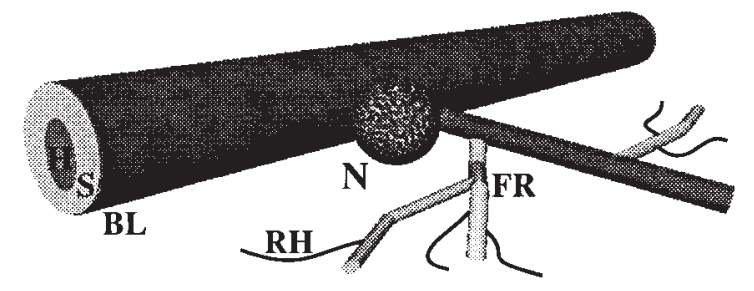

Figure 3. An idealized elementary unit (IEU) for functionalstructural root modeling. It contains bark (BL), sapwood (S), heartwood $(\mathrm{H})$, fine roots $(\mathrm{FR})$, root hairs $(\mathrm{RH})$, and nodules $(\mathrm{N})$.

sponds to our definition of IEU, is the stem segment including branching point and axillary buds at the upper end. The tree segment is composed of heartwood, sapwood, bark and the foliage cylinder surrounding the segment (figure 2). Thus, the geometry of the needles is taken into account by determining the width of the cylinder the needles form around the axis.

Following the shoot metamer analogy, we can define an IEU for woody transport roots as an internode between two branching events, or between a branching event and a root tip (figure 3). As is the case for the above-ground internode, the IEU of the transport roots consists of bark, sapwood and heartwood. The fine roots can be modeled as IEUs that terminate at the root tip. Most of them are short-lived, non-woody roots, which absorb soil nutrients and water, but some of the fine roots live longer and are converted into transport roots or, in the case of $\mathrm{N}_{2}$-fixing legume or actinorrhizal trees, into symbiotic nodules. This is analogous to the above-ground IEU meristems that can differentiate into either vegetative shoots or flowers, or even within an IEU into leaves or flowers, depending on intrinsic (e.g. meristem age) or external (e.g. day length) factors [3].

The results of physiological research can be linked with the FSM consisting of IEUs in a natural fashion. For example, the gas exchange of each leaf or growth segment can be estimated as a function of the micro environment of the IEU, and the results can summed up over the whole tree to estimate gas exchange at the tree level $[40,71,78,82]$. Also the aging-associated changes [70] are easy to take into account. Depending on the objectives of the FSM, a biochemically based $\mathrm{CO}_{2}$ exchange model [e.g. 14] or a model combining $\mathrm{CO}_{2}$ and $\mathrm{H}_{2} \mathrm{O}$ exchange $[6,57]$ can be applied. Alternatively, approaches that utilize the leaf density distribution and light attenuation in a clumped or turbid medium can be also used because, as the spatial positions of the IEUs are known, the necessary distribution functions can be assessed. In addition to photosynthesis, a number of other processes (e.g. 
transpiration) are involved in resource capture. Depending on the desired level of detail in the model, their effects can be incorporated an analogous fashion into the IEUs.

Nutrient-uptake models that utilize 2 or 3 D root architecture have also been designed (cf. Sect. 2.1.3 and this volume). The uptake of nutrients and water by a root IEU can be treated in an analogous manner to gas exchange in the above-ground parts: the local environment of the IEU and its state affect the uptake processes. An additional factor in below-ground modeling is the necessity to describe the soil heterogeneity and the influence of mycorrhizas on the description of the $3 \mathrm{D}$ distribution of the actual absorbing surface.

Resource capture may depend, not only on the local climate of the capturing organ, but also on its position within the tree. The latter response can vary depending on the functioning of the whole tree [87, 90]. Such effects can be incorporated into the FSMs in a straightforward way, since the FSMs contain accurate information about both the detailed structure and the state of the whole tree.

\subsection{Modeling the distribution of growth in the FSMs}

\subsubsection{Mechanisms influencing the distribution of growth}

The distribution of growth involves both the transport of substances from sources to sinks, and the utilization of the resources at the sinks. Transpiration and photosynthesis are the main driving forces for material transport at the tree level [18, 77]. The cohesion-adhesion theory [113] and the Münch theorem [99] describe the water and sugar flow phenomena. However, there are a number of processes that complicate the relatively clear picture given by these theories. The controlling mechanisms of sink strength (i.e. meristem activity) are poorly known. Successful tree development seems to presuppose that only a few specific buds grow and the rest either become dormant or abort [98]. The local environment also controls the development; light quality influences the number of buds and shoot extension [4], and it has been shown that the fine roots tend to grow towards nutrient rich microsites in the soil [111]. Secondary growth starts when the dormant buds start developing. Matching the nitrogen and carbon flows at the plant level is one of the key determinants directing plant development [101]. However, there is strong evidence that growth is controlled more by the sink strength than by the resource supply [2, 89]. Nitrogen availability is postulated to determine the meristem size and to influence, through this, the following year's growth [Millthorpe, this vol- ume]. The signal that has been proposed to control nodulation and nitrogenase activity in $\mathrm{N}_{2}$-fixing legumes in the absence of serious $\mathrm{C}$ limitation is the concentration of reduced $\mathrm{N}$ in the phloem flow entering the roots [76]. Whichever is the real mechanism, it is clear that they are all connected with the interaction between factors that influence the development of the transport capacity and the resulting material transport within the tree.

The distribution of growth that results from sourcesink relationships, material transport and tree-level control mechanisms can be technically incorporated into FSMs in a fairly straightforward manner. However, it is clear that so far our biological understanding of the processes involved has not supported very well this level of modeling. Therefore many less mechanistic approaches have been suggested for modeling the distribution of growth. They are usually based on establishing some sort of structural principle that applies to the whole tree. In the next sections we review these principles, as well as some mechanistic models for the distribution of growth. We also show how a structural principle (the pipe model theory) can be used to derive the distribution of growth in a FSM.

\subsubsection{Descriptive allometry}

Descriptive allometric [60] models assume predetermined ratios between the growth rates or relative growth rates of the organs. These ratios can change depending on the position of the trees in the stand [36] or on the developmental stage or age of the stand [64]. The models provide a simple description of the dry-matter distribution and are therefore easily incorporated into production models. However, they do not explain growth processes, and remain entirely empirical. Their use is limited by the sparse data on allocation in trees, as well as by the large variability in allocation depending on the environmental conditions or the size and age of the trees $[15,72,91]$.

\subsubsection{Allometric relationships}

The biomass allocation between tree parts can be derived from the assumption that certain allometric relationships exist between the different parts of trees. Generally it has been assumed that the size of one plant part can be expressed in terms of size of the another part [50]. When using the biomasses, the relationship (between parts $i$ and $j$ ) can be expressed as

$$
W_{i}=a W_{j}^{b}
$$

where $W$ stands for the biomass of the compartment, and $a$ and $b$ are empirical constants. If it is assumed that the allometric relationships remain unchanged over time or 
that the change is known, then it is possible to derive the distribution of total photosynthetic production to the different biomass compartments after first subtracting the respiration [95]. This general method thus relies on the relative sizes of different components, which have to be empirically determined. On the other hand, it is not clear how constant the relationships between different parts actually are and how they are affected by different environmental conditions [24, 29, 53]. The positive aspects are that the model structures can be made rather simple and that, using this approach, a relatively high proportion of the internal dynamics of forest stands can be described [95].

\subsubsection{Functional equilibrium and optimization}

Brouwer [11] introduced the concept of "functional equilibrium" between shoot and root growth. This concept emerged from the fact that the shoots are subordinated to the roots for their water and nutrient supply and, conversely, the roots depend on the leaves for their carbohydrate supply. It was thus assumed that a state of equilibrium exists between these two compartments. Based on this concept, [12, 109] models were developed in which partitioning coefficients between the shoot and roots are related to the functional equilibrium for water and carbon or carbon and nitrogen.

In a similar way, teleonomic or optimality methods have also been applied to allocation [56, 94], a specific function of the plant being maximized with respect to an allocation coefficient [103]. Teleonomy refers to "objects endowed with a purpose or project" [66], for instance the optimization of the relative growth rate permitted by the maintenance of the root/shoot equilibrium. In this approach the specific activities of the root and shoot regulate the partitioning of assimilates. The specific activities of the shoot and the root are largely controlled by the environmental conditions in which they grow. Thus, the optimization and functional balance seems to be well suited to describing or predicting partitioning in relation to changes in resource acquisition (incident radiation for photosynthesis, availability of nutrients). They may be, however, less suitable for managing the allocation to those organs which are not participating in the capture of the resources, i.e. flowers, fruits, or some parts of the root system.

\subsubsection{Transport/conversion model}

Thornley [101, 104] proposed the a mechanistic transport/conversion model for shoot/root partitioning in relation to the availability of carbon and nitrogen. In this approach, carbon and nitrogen substrates enter the plant through uptake processes, plant compartments are con- nected via transport pathways, and substrates are used for the growth of structural dry matter. Transport is proportional to concentration difference. The relative growth rates of the compartments depend on the concentrations of the substrates. Since Thornley's initial work, the approach has been improved by dividing the biomass into functional and structural compartments [39]. A typical application of the approach is the description of dry matter partitioning between the shoots and roots of plants and perhaps their different biomass compartments. More recently, the model has been extended to the growth of forest stands [102] and the formation of tree stem form [18]. Rigorous estimation of the parameters of the model requires an evaluation of both the resistance to transport in the vascular system, and of the pools of carbon and nitrogen. However, this is very time-consuming to do in practice. On the other hand, transport resistance and other parameters lend themselves to indirect estimation, which makes the application of the model easier. As discussed earlier, the actual transport process is much more complicated than that based simply on concentration differences. Also, the evidence seems to indicate that the sink strength is highly influenced by hormonal signals that further complicates the approach. From a theoretical view point, however, the transport resistance model reproduces the main features of partitioning and permits testing and improvement of the mechanistic assumptions [104].

\subsubsection{Source-sink relationships}

The source-sink approach considers the outcome of the partitioning of resources as the interaction between compartments [e.g. 21]. According to this, the flow between two elements (sink and source) is proportional to

(sink strength) $*$ (source strength) $*$ (distance factor),

where the distance factor is a function that decreases with increasing distance. Unlike transport/conversion approach that is based on mechanisms [101], the sourcesink approach has no mechanistic basis but it is only a plausible description of transport. On the other hand, the parameters of the source-sink model can be fitted with the aid of measurements, and it can be applied in conditions that are similar to those under which the measurements were made.

Models with potential demand functions assume that biomass allocation is primarily regulated by the potential growth rates of the sink organs. The sink strength is defined as the potential capacity of a sink to accumulate assimilates. This potential capacity, or potential demand, can be quantified by means of the potential growth rate of a sink, i.e. the growth rate under conditions of non-limiting assimilate supply. The potential growth rate may 
change with temperature or the developmental stage of a sink. The availability of assimilates is assumed to have no direct effect on the simulated dry matter distribution, but it can have indirect influences via its effects on the initiation and abortion of sinks. Like in the case of sourcesink approach, the main advantage of this type of model lies in the fact that it does not require specific knowledge of transport patterns, and carbon in different pools. It has given some promising results for tomato [42] and kiwi fruit [13]. However, these models have not yet been thoroughly validated. The main difficulty is to evaluate the potential growth rate of the different sinks.

\subsubsection{Pipe model theory}

A Pipe model is one of the most commonly used method to distribute resources between foliage and woody structures in PBMs [37, 55, 69, 78, 106]. The pipe model theory was initially proposed as a purely morphological model [93]. In its original form, it pictures a tree as consisting of unit pipes that connect each foliage element to the functional roots [93]. Pipes that end before the living crown become disused and form the heartwood [43, 93]. This theory predicts a linear relationship between foliage mass or area and the sapwood cross-sectional area below the crown (the slope of the relationship is called the Huber value in stem hydraulics) [37]. Both supporting and non-supporting evidence for the linear relationship between foliage quantity and sapwood area have been found in numerous studies $[1,7,8,24,38,43$, $44,53,108]$. Only a few studies on the actual dynamics between foliage area and sapwood area development have been published, but in these studies a linear relationship has been observed [69]. The overall conclusion from the empirical work is that, for some species, the pipe model is a very good approximate description of the relationship between foliage and wood growth. Despite this, there are also species for which it is does not hold.

A more general functional interpretation of the pipe model could be that, for its mechanical and physiological support, the foliage requires an infrastructure consisting of functional units. The amount of these units in any cross-section should be proportional a) to the amount of foliage above the point, and b) the structure of these units. This formulation easily lends itself to studying such problems as: how high a proportion of growth can be invested in the growth of a specific new (distal) element, and how much growth is required for the supporting pathway from the root to this particular element. With this approach we would also be able to consider the mechanical requirements of woody growth, which is another frequently used theory [110]. A simplification of the above formulation would be the traditional pipe model in which is stated that there is a constant ratio of foliage area or mass to the amount of functional wood area in the branches, stem and transport roots located below it.

\subsubsection{Fractal geometry and scaling}

Many branching systems that include shoot and root systems often exhibit a fractal nature. This means that a small portion of the system is an exact replica of it as a whole [58]. The form of an entire branching system is the result of the replicated iteration of elementary units [9]. Because of the iterative nature of the modular growth, the shoot and root systems contain nested similarity and hence lend themselves to modeling as fractals. In many cases, however, such complex objects as shoot or root systems cannot be presented by a single fractal. Hence, self affinity and multifractals are probably better suited for useful, simple descriptors that integrate much of the complex architecture of the plant. Self affinity defines an object that has similar form over a range of scale. Multifractals $[58,59]$ refer to objects whose variation of fractal dimensions depends on the nature of the processes or parameters that regulate their formation [107]. In cases where a fractal analysis does not show simple scaling properties, the observed complexity can be due to fundamentally different processes operating on different scales [9, 74].

Fractal investigations of plant systems can be classified into two types. Firstly, the analysis of the fractal geometry of actual branching systems in order to explore how fractal dimensions [112] vary between species, through ontogeny, in response to environmental stresses in relation to the size of the plant system and branching structure. Secondly, approaches based on topological scaling, i.e. scale independence of branching rules that are more appropriate to explore the processes of development i.e. module iteration within the plant [26]. The variations in scaling properties observed between topological orders may correspond to different functional components of plant branching systems [9]. Fractal geometry may therefore provide useful analytical tools for studies on tree structure and functions. The use of fractal geometry linked with pipe-model theory may be well suited to predict the distribution of dry matter within the root links, on the basis of easily measurable parameters such as tree stem diameter or the proximal root diameters for roots [67].

\subsubsection{Examples of allocation of growth in FSMs}

When any of the reviewed approaches to distribution of growth is applied in a FSM, it must be adapted to presenting of the tree as a collection of elementary units. The amount of work it requires varies among the approaches. In this subsection we analyze a few approaches. 
The transport/resistance approach [101] can be applied to any number of tree parts [cf. 102] since it does not make any assumptions about the size of the tree parts it is dealing with. It is thus readily applicable in the FSMs. The transport/resistance approach requires that differential or difference equations for rates of transport between the elements and consumption in the elements are stipulated. In the case of a branched tree crown consisting of a large number of IEUs, the numerical solution of the model may prove difficult [28]. The time step has to be very short in order to prevent numerical instability. As a result, the model may be computationally heavy. The use of specialized numerical methods or advanced mathematical means, e.g. partial differential equations [18], is one way of remedying the computational problems. One possible restriction to the use of the transport/resistance approach at the moment is that signals other than the resource concentration are most likely controlling the sink strength (cf. 3.2.1).

Like the transport/resistance approach, the source-sink approach (3.2.6) can be readily applied to FSMs [21]. The flow between two elements (sink and source) is proportional to their activities and mutual distance (3.2.6). Calculations based on such relationships are rather straightforward to apply in a tree consisting of elementary units: the potential sink or source strength can be modeled as an attribute of each IEU. One complicating factor is that it requires pairwise comparisons of the units, and hence makes the model potentially computationally intense. As the source-sink model must be fitted using measurements, it can be reliably applied only in similar conditions. It is thus comparable with approaches that use a structural principle (e.g. allometric relationships), the parameters of which are usually found empirically.

When the tree structure is described with the aid of a structural principle that applies to the tree as a whole (like allometric equations or pipe model), the principle has to be translated to the level of the elementary unit. How this is accomplished depends on the principle and the FSM. We give an example by showing how the pipe model is applied in the Lignum model $[78,96]$. The pipe model has been transformed into two main assumptions: 1) Wood growth in the most distal units is proportional to foliage growth and, since the foliage units are thought to be connected to roots by unit pipes, (see 3.2.7), it is assumed that 2) the cross-sectional area of the sapwood in an elementary unit connecting to units above is equal to the sum of cross-sectional areas of the units above (figure 4). Once the growth of foliage in the distal units is known, assumptions 1 and 2 make it possible to calculate the thickness growth all the way down to the base of the model tree. The cross-sectional area of sapwood is thus summed up downwards from the branch tips to the base

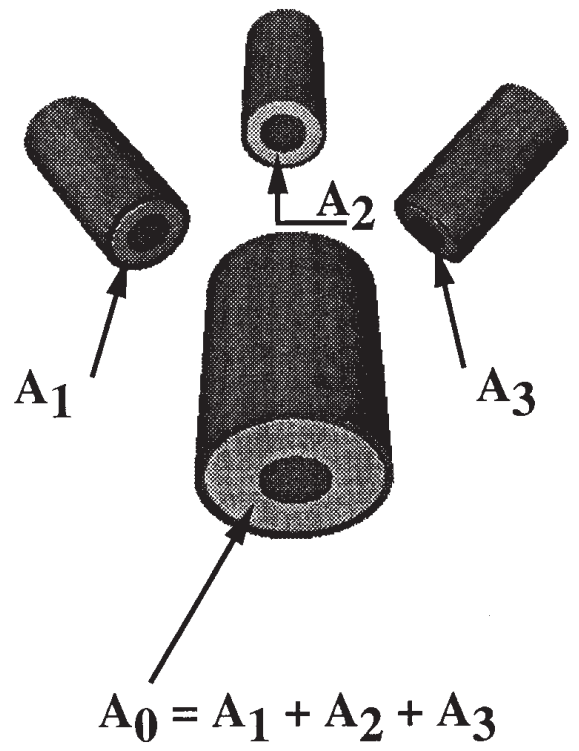

Figure 4. Illustration of the application of the pipe model theory at the elementary unit level in Lignum model [78] (woody part with bark is shown, sapwood is indicated with light grey color). It is assumed that, after every growth cycle, the crosssectional area of the sapwood $\left(A_{0}\right)$ in a elementary unit connecting to the units above is equal to the sum of the crosssectional areas of the units above $\left(A_{1}+A_{2}+A_{3}\right)$. The amount of pre-existing sapwood and heartwood formation affect the crosssectional areas of sapwood in the elementary units.

of the tree. The amount of pre-existing sapwood and heartwood formation are included in these calculations, thus making it possible to analyze the effects of physiological processes in the woody part on tree growth [78, 96].

\section{DISCUSSION}

We have analyzed the FSMs from the starting point that they contain features of both morphological models and the PBMs. The morphological models build on the research carried out on the regularities of plant form and emphasize the modularity of trees. The PBMs concentrate mainly on the driving processes behind the growth of trees, i.e. the material exchange between plant and its environment. A key component of these models is therefore the distribution of resources between tree organs. We have assumed that the importance of the distribution of growth carries over from the PBMs to the FSMs, and have given weight to it in our analysis. In the following sections we discuss matters of importance with regard to the FSMs. 


\subsection{Computational requirements}

The computer program implementing a FSM has to be able to deal with a potentially large number of elementary units that constitute the model tree. The model may involve components that are based on complicated mathematical calculations. If the model requires unit-to-unit interactions, the program can become computationally intense. Appropriate mathematical methods can be used to avoid too complex programs. As the FSM can be implemented as a computer program in various ways, suitable data structures and algorithms can be of prime importance for program speed and expandability. Computational problems may arise for example if:

1. The implementation of the model requires pairwise comparison of all the units of the model tree. In this type of problem the time complexity ${ }^{2}$ is proportional to the second power of the number of the units; we observe that doubling the number of units makes the running time fourfold. This situation may arise e.g. when the radiation extinction is treated as a geometrical problem [79];

2. The material transport is modeled using partial differential equations as, e.g. for the water flow in $3 \mathrm{D}$ tree crowns [28]. The natural form of discretization for the model tree is in terms of the elementary units. However, it is often the case that this discretization is too coarse for numerical methods, and it must be refined in order to increase accuracy. It is estimated that the computational complexity of solving a partial differential equation of one variable is maximally proportional to the third power of the number of points in the discretization. The number of points in discretization is generally equal to or greater than the number of elementary units in the tree. Thus, in the worst case, doubling the number of elementary units gives us a factor of eight in operations;

3. The processes vary in scale, say, that one model has to include the photosynthesis in the leaves and the growth over many years. It would be prohibitively expensive to use the resolution required by photosynthesis in every part of the model. The only way to overcome these difficulties is to employ different approaches whenever appropriate, and to simplify the interfaces between the submodels both from the point of view of materials and processes. The overall level of complexity can be brought to manageable levels in this manner. The reduction of complexity has been successfully achieved for example in nuclear power plant simula-

\footnotetext{
2 The time complexity can be thought of as the number of instructions (or program steps) the program requires on an idealized computer.
}

tion. The very small-scale problem of neutron-transport within the reactor core is glued to the macroscopic scale of the primary and secondary circuits [5]. The same idea can be applied in the FSMs, thus arranging the processes hierarchically and utilizing different time and space resolutions for different processes.

The above points show that computational problems are always looming around the corner when a FSM is used. The running time of the program may increase proportional to the second or third power of the number of elementary units. It is thus not possible in principle to deal with deliberately large trees (i.e. deliberately many units) using a FSM. What is the practical upper limit of units depends on the FSM. This limit is affected by the number of processes being considered, the time resolution of the model, and the chosen mathematical methods and algorithms. For example, the Lignum model [79] employs an accurate calculation of radiation in the tree crown, which leads to pairwise comparisons of the units and thus to computational complexity proportional to the second power of the number of the units. It has turned out that the maximum number of units which can be treated is 10000 when the program is run on a modern computer. This discussion shows that, whenever possible one should always stick to linear algorithms. By limiting the number of details that can be incorporated into FSMs, the computational limitations also impose constraints on the biological complexity that can be described with these models.

\subsection{Challenges and tasks of the FSMs}

We have identified some aspects that still present major challenges for functional-structural modeling. We have also marked down some applications in which we think FSMs will be successful in the near future.

We do not have a clear picture of all the mechanisms that influence the transport and growth processes. Consequently, up to now, the distribution of growth is not described mechanistically in any of the models. In most of the cases even the material balances are not considered. A large number of compounds are involved in transport processes. Some of them are present in such small concentrations that they are difficult to measure [99]. Therefore both the empirical basis of a mechanistic model that is based on treating the main compounds and its testing possibilities are poor. It thus seems that a mechanistic, multisubstrate model that could be applied in the complex 3D structure of FSMs is difficult to realize at the moment. On the other hand, the lack of methods for quantitative estimation of the role of different processes in the growth control may have hindered our ability for meaningful experimentation. A FSM may well serve as a 
test-bench for different hypotheses for tree level control, and guide experiments aimed at elucidating the role of various processes in the behavior of whole tree.

Modeling the root/mycorrhiza system poses a great challenge. To make progress, researchers will have to consider the hydraulic architecture of the root system [22] in order to be able to improve root water-uptake patterns with respect to the heterogeneous distribution of the water potential within the root system. Another important topic concerns the resolution of below-ground competition at the level of growing stands. Existing models are still partial, focussing mainly on physical soil transport processes (cf. [75]), rather than simulating transport on the basis of root properties, such as age, geometry, and spatial and temporal variations in root hydraulic resistance.

The complex and only partially known dynamic interaction between the populations of soil mycorrhizas and the root functions and architecture development probably poses as great a challenge for FSM modeling as the mechanistic description of the distribution of growth. In that case too, the modeling is heavily dependent on advances in this research field. The relatively well-known and structurally simple rhizobial or Frankia symbioses do not, as such, pose major problems in FSM development, but they strongly affect the carbon and nitrogen flows within a tree, and add an active $\mathrm{C}$ sink and $\mathrm{N}$ source for biomass allocation. The much less known cyanobacterial $\mathrm{N}_{2}$-fixing symbioses may pose important challenges for FSM as the research in this field advances. However, 3D modeling of the below-ground compartment of trees may also facilitate new forms of experimentation and analysis of the results.

FSMs require large amounts of data for initialization and parameter values. This fact, combined with the computational complexity, suggests that the FSMs may not be particularly suitable for large-scale problems, covering large forest stands or forested areas. In contrast, the value of FSMs versus more aggregated models may lie in the fact that they can produce theoretically justified responses of single plants or groups of plants to different environmental conditions.

Evaluating the benefits and constraints of FSMs on the basis of the points presented above, we suggest that they may be successful in the study of the following phenomena and issues of tree growth:

- Effect of spatial heterogeneity on early development of trees;

- Competition with surrounding vegetation;

- Growth of trees in a mixed species stand and understory seedling growth;

- Tree-herbivory interaction;
- Effects of tree pruning;

- Development of wood quality;

- In the search for tree ideotype;

- Scientific visualization of tree growth processes, especially in the context of teaching.

While the mechanistic bases for growth modeling are still open, the FSM approach facilitates at least an accurate phenomenological description of tree development. The success of morphological models in representing tree architecture shows that it is possible to capture the growth rules at that level. Linking bud differentiation and shoot growth with the local environment and position within the crown, and connecting this with a suitable distribution key such as the pipe model, gives us an useful tool for describing the structural dynamics of trees. It opens possibilities to predict tree growth and development at a new level of detail.

Acknowledgements: This research has been supported by the research grants No. 37090 and 28203 from the Academy of Finland.

\section{REFERENCES}

[1] Albrektson A., Sapwood basal area and needle mass of scots pine (Pinus sylvestris L.) trees in central Sweden, Forestry 57 (1984) 35-43.

[2] Aloni R., Differentiation of vascular tissues, Ann. Rev. Plant Physiol. 38 (1987) 179-204.

[3] Barthélémy D., Caraglio Y., Costes E., Architecture, gradients morphogénétiques et âge physiologique chez les végétaux, in: Bouchon J., de Reffye Ph., Barthélémy D. (Eds.), Modélisation et simulation de l'architecture des végétaux, INRA Éditions, Versailles, France, 1997, pp. 89-136.

[4] Ballaré C.L., Light Gaps: Sensing the Light Opportunities in Highly Dynamic Canopy Environments. in: Exploitation of Environmental Heterogeneity by Plants, Caldwell M., Pearcy R (Eds.), Academic Press. London, 1994.

[5] Bell G.I., Glasstone S., Nuclear reactor theory, Van Nostrand Rheinhold, New York, 1970.

[6] Berninger F., Mäkelä A., Hari P., Optimal control of gas exchange during drought: Empirical evidence, Ann. Bot. 77 (1996) 469-476.

[7] Berninger F., Mencucini M., Nikinmaa E., Grace J., Hari P., Evaporative demand determines branchiness of Scots Pine. Oecologia 102 (1995) 164-168.

[8] Berninger F., Nikinmaa E., Within tree and between site variation in the foliage area/sapwood area relationship in Scots pine stands in different climatic conditions, Can. J. For. Res. 24 (1994) 2263-2268.

[9] Berntson G.M., Scaling, and the description of plant root architecture, in: Plant Roots The Hidden Half. Waisel Y., Eshel 
A., Kafkafi U. (Eds.) - 2nd ed., rev. and expanded. MDI Dekker, New York, 1996, pp. 259-272.

[10] Breckling B., An individual based model for the study of pattern and process in plant ecology: An application of oject oriented programming, EcoSys 4 (1996) 241-254.

[11] Brouwer R., Functional equilibrium: sense or nonsense? Neth. J. Agric. Sci. 31 (1983) 335-348.

[12] Brouwer R., de Wit C.T., A simulation model of plant growth with special attention to root growth and its consequences, in Root Growth, Washington W.J. (Ed.) Butterworths, London, 1969, pp. 224-244.

[13] Buwalda J.G., The carbon cost of root systems of perennial fruit crops, Env. Exp. Bot. 32, 1 (1993) 131-140.

[14] Caemmerer von S., Farquhar G.D., Some relationships between the biochemistry of photosynthesis and the gas exchange of leaves, Planta 153 (1981) 376-387.

[15] Cannell M.G.R., Dry matter partitioning in tree crops, in Attributes of trees as crop plants, Cannell M.G.R. and Jackson J.E. (Eds.) Institute of Terrestial Ecology, Huntingdon, UK., 1985, pp. 194-207.

[16] Caraglio Y., Barthélémy D., Revue critique des termes relatifs à la croissance et à la ramification des tiges des végétaux vasculaires, in: Bouchon J., de Reffye Ph., Barthélémy D. (Eds.), Modélisation et simulation de l'architecture des végétaux, INRA Éditions, Versailles, France, 1997, pp. 11-87.

[17] Clausnitzer V., Hopmans J.W., Simultaneous modeling of transient three-dimensional root growth and soil water flow, Plant Soil 164 (1994) 299-314.

[18] Deleuze C., Houllier F., A transport model for tree ring width, Silva Fenn. 31 (1997) 239-250.

[19] Diggle A.J., ROOTMAP - a model in three-dimensional coordinates of the growth and structure of fibrous root systems, Plant Soil 105 (1988) 169-178.

[20] Dixon R.K., Meldahl R.S., Ruark G.A., Warren W.G., Process Modeling of Forest Growth Responses to Environmental Stress, Timber Press, Portland, Oregon, 1990.

[21] Le Dizès S., Cruiziat P., Lacointe A., Sinoquet H., Le Roux X., Balandier Ph., Jacquet P., A model for simulating structure-function relationships in walnut tree growth processes, Silva Fenn. 31 (1997) 313-328.

[22] Doussan C., Pagès L., Vercambre G., Modelling of the hydraulic architecture of root systems: an integrated approach to water absorption - Model description, Ann. Bot. 81 (1998) 213223.

[23] Eschenbach C., Modelling growth and development of black alder trees with an object oriented approach, ASU Newsletter 24 (1998) 75-86.

[24] Espinosa Bancalari M.A., Perry D.A., Marshall J.D., Leaf area- sapwood area relationships in adjacent young Douglas-fir stands with different early growth rates, Can. J. For Res. 17 (1987) 174-180.

[25] Fisher J.B., How predictive are computer simulations of tree architecture? Int. J. Plant Sci. 153, 3 (1992) 137-146.

[26] Fitter A.H., Characteristics and functions of root systems. In Plant Roots The Hidden Half. Waisel Y., Eshel A.,
Kafkafi U. (Eds.) - 2nd ed., rev. and expanded, MDI Dekker, New York, 1996, pp. 1-20.

[27] Friend A., Kellomäki S., Krujit B., Modelling leaf, tree, and forest responses to increasing atmospheric $\mathrm{CO}_{2}$ and temperature, in: Jarvis P.G. (Ed.) European Forests and Global Change, Cambridge University Press, Cambridge, 1998, pp. 293-334.

[28] Früh T., Simulation of water flow in the branched tree architecture, Silva Fenn. 31, 3 (1997) 275-284.

[29] Geron C.D., Ruark G.A., Comparison of constant and variable allometric ratios for predicting foliar biomass of various tree genera, Can. J. For. Res. 18 (1988) 1298-1304.

[30] Givnish T.J., Adaptation to sun vs. shade: A whole-plant perspective, Aust. J. Plant Physiol. 15 (1988) 63-92.

[31] Godin C., Guédon Y., Costes E., Caraglio Y., Measuring and analyzing plants with the AMAPmod software, in: Michaelewicz M. (Ed.), Advances in computational life sciences I: Plants to ecosystems, CSIRO, Australia, 1997, pp. 6394.

[32] Godin C., Caraglio Y., A multistiscale model of plant topology, J. Theor. Biol. 191 (1998) 1-46.

[33] Godin C., Guédon Y., Costes E., Exploration of a plant architecture database with the AMAPmod software illustrated on an apple tree hybrid, Agronomie 19 (1999) 163-184.

[34] Hallé F., Oldeman R.A.A., Tomlinson P.B., Tropical trees and forests: An architectural analysis. Springer-Verlag, Berlin, Germany, 1978, p. 441.

[35] Hanan J., Virtual plants - integrating archtectural and physiological models, Environmental Modelling \& Software 12, 1 (1997) 35-42.

[36] Hari P., Kellomäki S., Mäkelä A., Ilonen P., Kanninen M., Korpilahti E., Nygren M., Metsikön varhaiskehityksen dynamiikka. (Summary: Dynamics of early development of tree stand), Acta For. Fenn. 177 (1982) 42.

[37] Hari P., Kaipiainen L., Korpilahti E., Mäkelä A., Nilson T., Oker-Blom P., Ross J., Salminen R., Structure, radiation and photosynthetic production in coniferous stands, University of Helsinki, Department of Silviculture Research notes No. 54, 1985, p. 233.

[38] Hari P., Kaipiainen L., Heikinheimo P., Mäkelä A., Korpilahti E., Salmela J., Trees as a water transport system. Silva Fenn. 20, 3 (1986) 205-210.

[39] Hilbert D.W., Reynolds J.F., A model allocating growth among leaf proteins, shoot structure, and root biomass to produce balanced activity, Ann. Bot. 68, 5 (1992) 417-425.

[40] Host G.E., Rauscher H.M., Isebrands J.G., Michael D.A., Validation of photosynthate production in ECOPHYS, an ecophysiological growth process model of Populus, Tree Physiol. 7 (1990) 283-296.

[41] Jaeger M., Reffye Ph. de, Basic concepts of computer simulation of plant growth, J. Biosci. 17 (1992) 275-291.

[42] Jones J.W., Dayan E., Van Keulen H., Challa H., Modelling tomato growth for optimizing greenhouse temperatures and carbon dioxide concentrations, Acta Hort. 248 (1989) 285-294. 
[43] Kaipiainen L., Hari P., Consistensies in the structure of Scots pine, In Crop physiology of forest trees, Tigertsedt P.M.A., Puttonen P., Koski V. (Eds.) Helsinki University Press, 1985, pp. 31-38.

[44] Keane M.G., Weetman G.F., Leaf area - sapwood cross-sectional area relationships in repressed stands of lodgepole pine, Can. J. For. Res. 17 (1987) 205-209.

[45] Kellomäki S., Strandman H., A model for the structural growth of young Scots pine crowns based on light interception by shoots, Ecol. Modell. 80 (1995) 237-250.

[46] Küppers M., List R., MADEIRA - A simulation of carbon gain, allocation, canopy architecture in competing woody plants, in: Jeremonidis G., Vincent J.F.V. (Eds.) Plant Biomechanics 1997, conference proceedings I: papers, Centre for Biomimetics, The University of Reading, UK., 1997, pp. 321-329

[47] Kurth W., Growth Grammar Interpreter GROGRA 2.4. A software tool for the 3-dimensional interpretation of stochastic, sensitive growth grammars in the context of plant modelling, Introduction and reference manual, Berichte des Fortschungszentrums Waldökosysteme, Ser. B38, Göttingen, Germany, 1994, p. 192.

[48] Kurth W., Morphological models of plant growth: Possibilities and ecological relevance, Ecol. Modell. 75-76 (1994) 299-308.

[49] Kurth W., Sloboda B., Growth grammars simulating trees - an extension of L-systems incorporating local variables and sensitivity, Silva Fenn. 31 (1997) 285-295.

[50] Landsberg J.J., Physiological ecology of forest production, Academic Press, London, U.K., 1986, p. 198.

[51] Landsberg J.J., Gower S.T., Applications of Physiological Ecology to Forest Management, Academic Press, London, 1997.

[52] Lewis P., 3-D plant modelling for remote sensing studies using the Botanical Plant Modelling System, Agronomie 19 (1999) 185-210.

[53] Long J.N., Smith F.R., Leaf area- sapwood area relations of lodgepole pine as influenced by stand density and site index, Can. J. For. Res. 18 (1988) 247-250.

[54] Lungley D.R., The growth of root systems - A numerical computer simulation model, Plant Soil 38 (1973) 145-159.

[55] Mäkelä A., Implications of the pipe model theory on dry matter partitioning and height growth in trees, J. Theor. Biol. 123 (1986) 103-120.

[56] Mäkelä A., Sievänen R., Comparison of two shoot-root partitioning models with respect to substrate utilization and functional balance, Ann. Bot. 59 (1987) 129-140.

[57] Mäkelä A., Berninger F., Hari P., Optimal control of gas exchange during drought: Theoretical analysis, Ann. Bot. 77 (1996) 461-467.

[58] Mandelbrot B.B., The fractal geometry of nature, Freeman, New York, 1983.

[59] Mandelbrot B.B., An introduction to multifractal distribution functions, In Fluctuations and Pattern Formation, Stanley H.E., Ostrowsky N. (Eds.), Kluwer, Dordrecht, The Netherlands, 1988.
[60] Marcelis L.F.M., Simulation of biomass allocation in greenhouse crops - A review, Acta Hor. 328 (1993) 49-67.

[61] Mĕch R., Prusinkiewicz P., Visual models of plants interacting with their environment, Computer Graphics proceedings, Annual Conference Series, SIGGRAPH 96, New Orleans, Louisiana, August 4-9, 1996, pp. 397-410.

[62] Mercer L., Prusinkiewicz P., Hanan J., The concept and design of a Virtual Laboratory, in: Graphics Interface ' 90 Conference proceedings, Canadian Information Processing Society, 1990, pp. 149-155.

[63] Middelhoff U., An object oriented model developing competing root systems of black alder-trees, ASU Newsletter 24 (1998) 65-74.

[64] Mohren G.M.J., Simulation of forest growth, applied to Douglas fir stand in the Netherlands, Pudoc, Wageningen, 1987, p. 184

[65] Mohren G.M.J., Kramer K., Sabaté S., Impacts of Global Change on Tree Physiology and Forest Ecosystems, Kluwer Academic Publishers, Dordrecht, 1997.

[66] Monod J., Chance and necessity, Glasgow: Collins Fontana Books, 1972.

[67] Noordwijk van M., Spek L.Y., De Willingen P., Proximal root diameters as predictors of total root system size for fractal branching models. I. Theory, Plant Soil 164 (1994) 107-118.

[68] Nielsen K.L., Lynch J.P., Jablokow A.G., Curtis P.S., Carbon cost of root systems: An architectural approach, Plant Soil 165 (1994) 161-169.

[69] Nikinmaa E., Analyses of the growth of Scots Pine; matching structure with function, Acta For. Fenn. 235, 1992.

[70] Nygren P., Leaf $\mathrm{CO}_{2}$ exchange of Erythrina poeppigiana (Leguminosae: Phaseoleae) in humid tropical field conditions, Tree Physiol. 15 (1995) 71-83.

[71] Nygren P., Kiema P., Rebottaro S., Canopy development, $\mathrm{CO}_{2}$ exchange and carbon balance of a modeled agroforestry tree, Tree Physiol. 16 (1996) 733-745.

[72] Ovington J.D., Dry-matter production of Pinus sylvestris L, Ann. Bot. 21 (1957) 287-314.

[73] Ozier-Lafontaine H., Lafolie F., Bruckler L., Tournebize R., Mollier A., Modelling water competition in intercrop: Theory and comparison with field experiment, Plant Soil 204 (1998) 183-201.

[74] Ozier-Lafontaine H., Lecompte F., Sillon J.F., Fractal analysis of the root architecture of Gliricidia sepium for the spatial prediction of root branching, size and mass, Model development and evaluation in agroforestry, Plant Soil 209 (1999) 167-180.

[75] Pagès L., Jordan M.O., Picard D., A simulation model of the three-dimensional architecture of the maize root system, Plant Soil 119 (1989) 147-154.

[76] Parsons R., Stanforth A., Raven J.A., Sprent J.I., Nodule growth and activity may be regulated by a feedback mechanism involving phloem nitrogen, Plant Cell Environ. 16 (1993) 125-136.

[77] Pate J.S., Jeschke W.D., Role of Stems in Transport, Storage, and Circulation of Ions and Metabolites by the Whole 
Plant, In: Plant Stems Physiology and Functional Morphology. Gartner B.L. (Ed.) Academic Press, san Diego, 1995, pp. 177204.

[78] Perttunen J., Sievänen R., Nikinmaa E., Salminen H., Saarenmaa H., Väkevä J., LIGNUM: A tree model based on simple structural units, Ann. Bot. 77 (1996) 87-98.

[79] Perttunen J., Sievänen R., Nikinmaa E., LIGNUM: A model combining the structure and functioning of trees, Ecol. Modell. 108 (1998) 189-198.

[80] Prusinkiewicz P., Lindenmayer A., The Algorithmic Beauty of Plants, Springer-Verlag, Berlin, 1990.

[81] Prusinkiewicz P., Hammel M., Hanan J., Mĕch R., Visual models of plant development, in: Rozenberg G., Salomaa A. (Eds.), Handbook of Formal Languages, Vol. 3, Springer, Berlin, 1996, pp. 535-597.

[82] Rauscher H.M., Isebrands J.G., Host G.E., Dickson R.E., Dickmann D.I., Crow T.R., Michael D.A., ECOPHYS: An ecophysiological growth process model for juvenile poplar, Tree Physiol. 7 (1990) 255-281.

[83] Reffye Ph. de, Houllier F., Blaise F., Barthélémy D., Dauzat J., Auclair D., A model simulating above- and belowground tree architecture with agroforestry applications, Agrofor. Syst. 30 (1995) 175-197.

[84] Reffye Ph. de, Fourcaud T., Blaise F., Barthélémy D., Houllier F., A functional model of tree growth and tree architecture, Silva Fenn. 31 (1997) 297-311.

[85] Reffye Ph. de T., Blaise F., Chemouny S., Jaffuel S., Fourcaud T., Houllier F., Calibration of hydraulic growth model on the architecture of cotton plants, Agronomie 19 (1999) 265280.

[86] Rey H., Godin C., Guédon Y., Vers une représentation formelle des plantes, in: Bouchon J., de Reffye Ph., Barthélémy D. (Eds.), Modélisation et simulation de l'architecture des végétaux, INRA Editions, Versailles, France, 1997, pp. 139-171.

[87] Room P.M., Maillette L., Hanan J.S., Module and metamer dynamics and virtual plants, Adv. Ecol. Res. 25 (1994) 105-157.

[88] Salminen H., Saarenmaa H., Perttunen J., Sievänen Nikinmaa E., Väkevä J., Modelling Trees Using an ObjectOriented Scheme, Math. Comp. Mod. 20, 8 (1994) 49-64.

[89] Savidge R.A., Wareing P.F., Plant growth regulators and the differentiation of vascular elements, in: "Xylem cell development", Barnett J.R. (Ed.), Castle House Publications Ltd, Tunbridge Wells, Kent., 1981, pp. 192-235.

[90] Schulze E.D., Carbon dioxide and water vapour exchange in response to drought in the atmosphere and in the soil, Ann. Rev. Plant Physiol. 37 (1986) 247-74.

[91] Sheppard L.J., Ford. E.D., Genetic and environmental control of crown development in Picea sitchensis and its relation to stem wood production, Tree Physiol. 1 (1986) 341-352.

[92] Shibusawa S., Modelling the branching growth fractal patterns of the maize root system, Plant Soil 165 (1994) 339347.

[93] Shinozaki K., Yoda K., Hozumi K., Kira T., A quantitative analysis of plant form - the pipe model theory. I: Basic analyses, Jpn. J. Ecol. 14 (1964) 97-105.
[94] Sievänen R., Hari P., Orava J., Pelkonen P., A model for the effect of photosynthate allocation and soil nitrogen on plant growth, Ecol. Modell. 41 (1988) 55-65.

[95] Sievänen R., A process-based model for dimensional growth of even-aged stands, Scand. J. For. Res. 8 (1993) 28-48.

[96] Sievänen R., Nikinmaa E., Perttunen J., Evaluation of importance of sapwood senescence on tree growth, Silva Fenn. 31 (1997) 329-340.

[97] Sims D.J., Pearcy R.W., Photosynthetic Acclimation to Varying Light: A Leaf to Whole-Plant Perspective. In Exploitation of Environmental Heterogeneity by Plants, Caldwell M., Pearcy R. (Eds.) Academic Press. London, 1994.

[98] Stafstrom J.P., Developmental Potential of Shoot Buds. In: Plant Stems Physiology and Functional Morphology. Gartner B.L. (Ed) Academic Press, san Diego, 1995, pp. 257279.

[99] Taiz L., Zeiger E., Plant physiology. Benjamin/Cummings Publishing Company, Redwood City, CA, USA, 1991, p. 565.

[100] Takenaka A., A simulation model of tree architecture development based on growth response to local light environment, J. Plant Res. 107 (1994) 321-330.

[101] Thornley J.H.M., A balanced quantitative model for root:shoot ratios in vegetative plants, Ann. Bot. 36 (1972) 431441.

[102] Thornley J.H.M., A Transport-resistance model of Forest Growth and Partitioning, Ann. Bot. 68 (1991) 211-226.

[103] Thornley J.H.M., Shoot:root allocation with respect to $\mathrm{C}, \mathrm{N}$ and $\mathrm{P}$ : Investigation and comparison of resistance and teleonomic models, Ann. Bot. 75 (1995) 391-405.

[104] Thornley J.H.M., Modelling allocation with transport/conversion processes, Silva Fenn. 31, 3 (1997) 341-355.

[105] Thornley J.H.M., Johnson I.R., Plant and Crop Modelling; A Mathematical Approach to Plant and Crop Physiology, Clarendon Press, Oxford, 1990, p. 669.

[106] Valentine H.T., Tree-growth models: derivations employing the pipe model theory, J. Theor. Biol. 117 (1985) 579-584.

[107] Vicseck T., Fractal growth phenomena, 2nd ed. World Scientific, Singapore, 1992.

[108] Waring R.H., Schroeder P.E., Oren R., Application of pipe model theory to predict canopy leaf area, Can. J. For. Res. 12 (1982) 556-560.

[109] Wit C.T. de, Penning de Vries F.W.T., Predictive models in agricultural production, Phil. Trans. Roy. Soc., London. B. 310 (1985) 309-315.

[110] Ylinen A., Über die mechanische Schaftformtheorie der Bäume, Silva Fenn. 76 (1952) 1-52.

[111] Zhang H., Forde B.G., An Arabidopsis MADS box gene that controls nutrient-induced changes in root architecture, Science 279 (1998) 407-409.

[112] Zeide B., Pfeiffer P., A method for estimation of fractal dimension of tree crowns, For. Sci. 37 (1991) 1253-1265.

[113] Zimmermann M.H., Xylem structure and the ascent of sap, Springer-Verlag, Berlin, Germany, 1983, p. 143. 